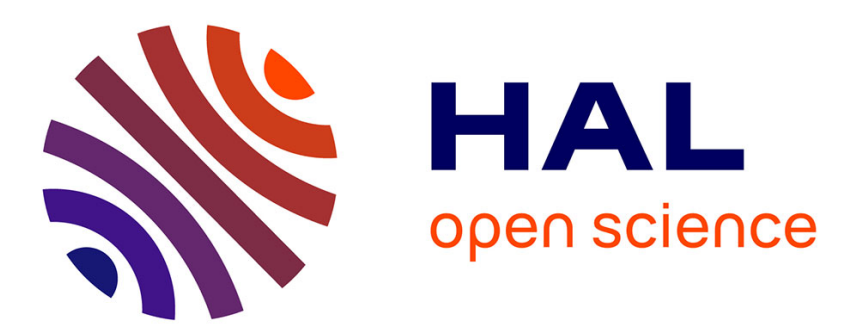

\title{
Botulinum neurotoxin injection for the treatment of epiphora in nasolacrimal duct obstruction
}

Brigitte Girard, Jean-Marie Piaton, Pierre Keller, Chantale Abadie, T.H.

Nguyen

\section{- To cite this version:}

Brigitte Girard, Jean-Marie Piaton, Pierre Keller, Chantale Abadie, T.H. Nguyen. Botulinum neurotoxin injection for the treatment of epiphora in nasolacrimal duct obstruction. Journal Français d'Ophtalmologie, 2017, 40 (8), pp.661-665. 10.1016/j.jfo.2017.03.006 . hal-03201734

\section{HAL Id: hal-03201734 \\ https://hal.sorbonne-universite.fr/hal-03201734}

Submitted on 19 Apr 2021

HAL is a multi-disciplinary open access archive for the deposit and dissemination of scientific research documents, whether they are published or not. The documents may come from teaching and research institutions in France or abroad, or from public or private research centers.
L'archive ouverte pluridisciplinaire HAL, est destinée au dépôt et à la diffusion de documents scientifiques de niveau recherche, publiés ou non, émanant des établissements d'enseignement et de recherche français ou étrangers, des laboratoires publics ou privés. 


\section{TITLE:}

NEUROTOXIN BOTULINUM A IN THE TREATMENT OF EPIPHORA IN

\section{LACRIMAL DUCTS OBSTRUCTION}

AUTHORS :

GIRARD Brigitte ${ }^{1,2}$, PIATON Jean-Marie ${ }^{3}$, KELLER Pierre ${ }^{3}$, ABADIE Chantale ${ }^{4}$, NGUYEN Rosalie 5 .

\section{CORRESPONDING AUTHOR:}

Brigitte GIRARD, MD

${ }^{1}$ Department of Ophthalmology, Hopital Tenon, GHU Est -Parisien, 4, rue de la Chine, 75970 Paris Cedex 20, France

Department V of Ophthalmology, Quinze-Vingts National Hospital of Ophthalmology, 28, rue de Charenton, 75012 Paris, France

Tel: +33 (0)1 56016436; Fax: +33(0)156017721

e-mail: docteur.girard@orange.fr

\section{Co-AUTHORS:}

Jean-Marie PIATON, MD

${ }^{3}$ Department IV of Ophthalmology, Quinze-Vingts National Hospital of Ophthalmology, 28 rue de Charenton, F-75012, Paris, France

e-mail: jmpiaton@yahoo.fr 
Pierre KELLER, MD

${ }^{3}$ Department IV of Ophthalmology, Quinze-Vingts National Hospital of Ophthalmology, 28 rue de Charenton, F-75012, Paris, France

e-mail: docteurkeller@orange.fr

Chantale ABADIE, MD

${ }^{4}$ Department of Ophthalmology, CHU CAEN

, France

Email : abadie.chantal@wanadoo.fr

\section{Rosalie NGUYEN, MD}

${ }^{3}$ Department of Neuroradiology, Quinze-Vingts National Hospital of Ophthalmology, 28 rue de Charenton, F-75012, Paris, France

Email : rnguyen@15-20.fr

Brigitte GIRARD, MD 
_epiphora_

Consultant pour Merz Pharma France et Ipsen.

Jean-Marie PIATON, MD pas d'interet à déclarer

Pierre KELLER, MD pas d'interet à déclarer

Chantale ABADIE, MD pas d'interet à déclarer

Rosalie NGUYEN, MD pas d'interet à déclarer 
TITLE:

BOTULINUM NEUROTOXIN INJECTION FOR THE TREATMENT OF EPIPHORA IN LACRIMAL DUCTS OBSTRUCTION

KEY-WORDS :

Epiphora

Tear

Lacrimal outflow obstruction

Botulinum neurotoxin A

Ptosis

diplopia 


\section{Abstract}

Headings: Retrospective long-term study to evaluate the efficacy of botulinum neuro-toxin A (BoNT/A) therapy in non- surgical obstructive lacrimal duct epiphora.

Background/aims : BoNT/A has been used successfully since 2000 in axillary hyperhidrosis to reduce secretory disorders. Some isolated cases of hyperlacrimation or crocodile tear syndrome have been treated on this basis. We used BoNT/A to decrease lacrimal secretion in epiphora.

Methods: We reviewed the qualitative and quantitative degree of improvement of epiphora after Botulinum Neurotoxin injections in the palpebral lobe of the lacrimal gland, carried out in an ophthalmic centre between 2009 and 2016. Epiphora was graded using questionnaire, Munk scores and Schirmer tests before and after injections. Severity of side effects was recorded.

\section{Results}

Twenty seven palpebral lacrimal glands of twenty patients with epiphora, mean age $65 \pm 13$, were treated with BoNT/A (BOTOX® or XEOMIN®) from April 2009 to April 2016. The epiphora was induced by lacrimal duct stenosis persistent after surgical treatment. No conventional medical nor surgical treatment was effective at this time. The technique of injection, dilution and dosage were specific. We re-injected 15/27 cases as asked and needed, $7 / 27$ cases three times, $3 / 27$ cases four times, and 2/27 cases (same patient both glands) five times.

The Schirmer test measured a decrease of lacrimal secretion in 24/27 (89\%) lacrimal glands after neurotoxin injection. Side effects were ptosis in 4 cases and transient esotropia in 2 cases. The authors describe the injection techniques, the dosage, the volume and concentration of BoNT/A. 


\section{Conclusion:}

Patients with epiphora can be treated effectively with BoNT/A to reduce lacrimal secretion of the principal lacrimal gland in its palpebral portion. Ninety per cent of the patients were very satisfied with few side effects (ptosis or mild diplopia lasting from 3 days to 3 weeks). More studies are needed to precise which epiphora can be treated with BoNT A. 


\section{INTRODUCTION}

Since 2000, botulinum neurotoxin A (BoNT/A) has been used successfully in axillary hyperhidrosis to reduce secretory disorders [1]. Since then, BoNT/A has been used in various sweating disorders such as axillary hyperhidrosis, palmar hyperhidrosis, drooling and gustatory sweating. Some isolated cases of hyperlacrimation or crocodile tear syndrome (CTS) have been treated on this basis [2]. BoNT/A blocks the release of acetylcholine in parasympathetic nerves, sympathetic preganglionic nerves and sympathetic postganglionic lacrimal fibres. We used BoNT/A to decrease lacrimal secretion in epiphora. We report a retrospective study to evaluate the efficacy of botulinum neurotoxin A (BoNT/A) in the treatment of epiphora owing to lacrimal outflow obstruction.

\section{MATERIALS AND METHODS}

\section{PATIENTS}

We treated 20 patients ( 27 glands) with epiphora due to lacrimal outflow obstruction, mean age of 65 years old $(\mathrm{SD}=13)$, age range of $37-85$. Sex ratio was $0.43,6$ men ( 5 with bilateral obstructive lacrimal outflow) mean age 67 years old $\pm 8,56$ and 14 women ( 2 with bilateral obstructive lacrimal outflow) mean age 63 years old $\pm 16,45$, with BoNT/ A since 2009. The patients were referred to Quinze-Vingts National Hospital of Ophthalmology, Paris, France, for diagnosis and treatment of their epiphora. The patients underwent a complete ophthalmic examination including control of lacrimal ducts permeability with injection by the inferior lacrimal point of a mixture of saline and fluorescein solution (FLUO®). The lacrimal duct wash up could be done under pressure to evaluate the severity of obstruction of the lacrimal duct. In case of obstruction, the lacrimal duct was tested by superior lacrimal point. A dacryoscanner with injection in lacrimal duct was programmed for most of them. No medical 
treatment was effective previously, and if surgery had been performed previously and failed, it could not be repeated. The aetiology of the epiphora was: complete phimosis of punctum lacrimal (4 cases), fibrosis to complete stenosis of lacrimal canalicular ducts after surgery (13 cases), lacrimonasal duct obstruction with bony obstruction (4 cases), canalicular or lacrimal duct stenosis with unsuccessful surgery of dacryocystorhinostomia (3 cases), failure of Métaireau tube (bilateral case in a Down syndrome patient) and one case of basocellular internal canthus tumor treated by surgery and radiotherapy. The patients refused any further surgery and preferred BoNT/A injections. To understand the severity of the epiphora, and control the follow up, the Munk score, questionnaire and Schirmer test were performed. All the patients underwent a dacryo-scanner with injection of lipiodol in the lacrimal canalicular to explore the level of the stenosis. These 27 epiphora presented a severe stenosis of the lacrimal duct, involving either lacrimal punctum, canalicular duct or lacrymo-nasal duct.

\section{METHODS}

After providing full information to the patient and recording their informed consent, we carried out a single BoNT/A injection transconjonctivally under direct visualisation with high magnification in the principal lacrimal gland, limited in its palpebral portion, avoiding the vessels, under topical anaesthesia (oxybuprocaïn UD). We used OnabotulinumtoxinA (Botox $\left.{ }^{\circledR}\right)$ in 3 glands and IncobotulinumtoxinA (Xeomin $\left.{ }^{\circledR}\right)$ in 24 glands. The patient was tilted in a semi-lying position in a surgical armchair. The injection was performed by an experienced ophthalmologist, under visual control with visual magnification, and extra additional light. The injection used a 1-ml syringe with a 30-gauge needle. BoNT/A volume injected was $0.01 \mathrm{ml}$ to $0.2 \mathrm{ml}$, with an average of $0.032 \mathrm{ml} / \mathrm{gland}(\mathrm{SD}=0,038)$. The concentration of the BoNT/A was $200 \mathrm{U} / \mathrm{ml}$ after reconstitution with saline solution. The mean 
total dosage of BoNT/A injected was 5.2 Units ( $S D=2.3$ units), range of $2-10 \mathrm{U}$. The follow up was at 1 month, three months and every six months post injection. We performed re-injection on patients' demand and repeated as needed. The time interval for re-injection was variable, with a mean interval of 10 months (SD : 7), range : 3-24 months.

\section{RESULTS}

We injected 27 palpebral lacrimal gland with Botulinum neurotoxin A for severe epiphora lasting for at least one year and related to lacrimal duct obstruction. This case series involved 20 patients, 6 men and 14 women, 65 years old \pm 13 . We treated 5 right lacrimal glands (4 men, 1 woman), 8 left lacrimal glands (1 man, 7 women) and 7 bilateral lacrimal glands (1 man, 6 women).

We used OnabotulinumtoxinA (Botox $\left.{ }^{\circledR}\right)$ in 3 glands and IncobotulinumtoxinA (Xeomin $\left.{ }^{\circledR}\right)$ in 24 glands. The concentration used was $200 \mathrm{u} / \mathrm{ml}$ for both Botulinum toxin formulations. BoNT/A volume injected was $0.01 \mathrm{ml}$ to $0.2 \mathrm{ml}$, with an average of $0.032 \mathrm{ml} / \mathrm{gland}$ $(\mathrm{SD}=0,038)$. The mean total dosage of BoNT/A injected was 5.2 Units ( $\mathrm{SD}=2.3$ units), range of $2-10 \mathrm{U}$, median $4 \mathrm{U}$.

The improvement was recorded on a subjective questionnaire, Munk score (Table 1) and Schirmer test. The questionnaire results were very encouraging with improvement of daily life activities such as driving, walking outside, watching TV or reading books. The relief described by the patients was spectacular. They were much happier with life, without needing to hold handkerchief s all day, without their vision blurring while watching. They could walk and work without tearing. Ladies could use make up again. Munk score (table 2) showed a dramatic improvement from mean score before injection at $3.88( \pm 0.3)$ to mean score after injection at $0.5( \pm 0.8)$. This result is statistically significant $(\mathrm{p}<0.0001)$. The Schirmer test 
had shown real improvement. Schirmer test (at 5 minutes, without local anesthesia) was at mean $35 \mathrm{~mm}$ before injection, range of 5-50 mm, SD 18 and median of $40 \mathrm{~mm}$. After injection, the Schirmer test had decreased to $13 \mathrm{~mm}$ mean, range of 5-30mm, SD 2.5, median $12 \mathrm{~mm}$. The improvement of epiphora screened with Schirmer test is significant with $\mathrm{p}<0.0001$. BoNT/A do not induced eye-dryness after BoNT/A injection.

After a first injection in the palpebral lacrimal gland, 9/27 glands (33\%) stopped tearing excessively. Results at the first injection 6 months later show a high level of satisfaction: excellent for $62 \%$ (17/27), mild for $31 \%(8 / 27)$ and no efficacy for $2(7 \%)$. Complications were limited to mild non obstructive ptosis in 4 cases lasting 1 week to 4 weeks, diplopia in one case lasting 3 weeks and a case of esotropia decompensation with little worrying as blurring TV watching, lasting a week. All the patients came to a follow up visit.

-Twelve patients out of 20 (14 glands/27) asked to be re injected once, as needed after a mean remission period of 7 months (range 1-24 months), $\mathrm{SD}=5.5$ months, median 3.5 months. In this second series, complications were limited to mild non obstructive ptosis in 4 cases and no diplopia.

-Six patients (7 glands) asked to be reinjected a third time after 6.7 months (range 2-11) with no complication except a no lasting esotropia.

-Two patients asked for a forth injection after 6 months (range 5-7) and one of them asked for a fifth injection after 6 months. No complications occured.

Complications observed for all injections are summarized in table 3.

We recorded no systemic adverse events. 


\section{DISCUSSION}

Botulinum toxin treatment for hyperlacrimation has been introduced in the therapy since 1999-2002 [1-4] for crocodile's tears. BoNT/A has been used in the treatment of autonomic nerve disorders and has been shown to be effective even in localised autonomic disorders including palmar and plantar hyperhidrosis, axillary hyperhidrosis, and Frey's syndrome [5,6]. Past treatments have included anticholinergic drugs, subtotal resection of the palpebral lobe of the lacrimal gland, and resection of the tympanic nerve. These approaches are aggressive and unsatisfactory because of limited efficacy and heavy morbidity explaining the development of BoNT/A therapeutic approach $[7,8,9]$. BoNT/ A injection technique for hyperlacrimation was established transconjonctivally into the palpebral lobe of the lacrimal gland.[10] We used high magnification glasses, the patient sitting on a surgical armchair, to be precise under direct visualisation in the localisation of injection that could determine the frequency of ptosis if injected near the superior palpebral levator. Others used the magnification of the slit lamp [7]. We chose not to inject under slit-lamp although the light and the magnification would be correct, to avoid an uncontrolled patient head movement during the injection. The injection involves only the palpebral portion of the principal lacrimal gland, not to affect lacrimal secretion from orbital portion of the principal lacrimal gland and to avoid a dry eye syndrome. The patient and the practitioner positions remain important to localise the palpebral portion of lacrimal gland. Patients injected transcutaneously in other studies developed ptosis, or superior rectus palsy [11].

We injected $4 \mathrm{U}$ on average ( $\mathrm{SD} \pm 2.3$ ) of OnabotulinumtoxinA or IncobotulinumtoxinA, a higher dosage of BoNT/A than Barañano and Miller [12], and Wojno [13] who injected 2,5 U of OnabotulinumtoxinA. Our patients developed a slightly higher incidence of transient ptosis 
or diplopia, while also higher rate of satisfaction (Table 4). The quantity injected is variable considering authors from 1-10 UA (OnabotulinumtoxinA) [14]. The trend seems to choose OnabotulinumtoxinA or IncobotulinumtoxinA, and disregard AbobotulinumtoxinA

(Dysport $\left.{ }^{\circledR}\right)$ due to higher proportion of ptosis [11] (4 cases). The level of satisfaction is high, above $70 \%[13,14,15]$ and up to $90 \%$ in our series (Table 4).

The patient's epiphora resolved within 1 to 7 days, 5 days for Barañano.[12] in CTS, 2 weeks later for Wojno [13]. The long lasting reduction of lacrimal secretion, compared with blepharospasm for instance, is also reported in the literature. Epiphora remains asymptomatic for 7 months on average in our experience after the first injection, 10 weeks in Ziahosseini et al [14]. Re- injection of BoNT/A was still effective, experiencing relief of epiphora at each injection as described in the others studies $[13,14,15]$. The higher dosage seems to have no additional benefit in terms of efficacy or duration but increases the local complications such as ptosis in our experience. Only three cases series have been reported in the literature on the treatment of epiphora in obstructive lacrimal ducts with BoNT/A [13-15]. This is the first series on the treatment of epiphora in obstructive lacrimal ducts with IncobotulinumtoxinA (Xeomin $($ ). At the beginning of our series, we injected up to 10U [16]. As the experience improved, the patients were injected to lower dosage (2 -4 U). This dosage appears effective and sufficient, with a lower rate of transient complications, correlated with last study [14]. Patients with previous malignancy involving lacrimal ducts can be rid of their epiphora with this new therapy.

Table 4

\begin{tabular}{|l|l|l|l|l|}
\hline & BG et al & Wojno & Whittaker & Ziahosseini \\
& & {$[13]$} & {$[15]$} & {$[14]$} \\
\hline
\end{tabular}




\begin{tabular}{|l|l|l|l|l|}
\hline $\begin{array}{l}\text { Mean } \\
\text { units/gland }\end{array}$ & $2-10 \mathrm{U}$ & $2.5 \mathrm{U}$ & $2.5-5 \mathrm{U}$ & $2.5-7,5 \mathrm{U}$ \\
\hline N. Lacrimal & 27 & 27 & 11 & 22 \\
\hline Elands & & & & \\
\hline ptosis & 14 & 11 & 18 & 0 \\
\hline Diplopia & 7 & 74 & 75 & 70 \\
\hline dryness & 0 & 0 & 18 & 12 \\
\hline hematoma & 0 & 0 & 0 & 0 \\
\hline
\end{tabular}

Injection of Botulinum toxin A for treatment appears to be safe, although minor complications. It is encouraging to be able to report that repeated injections of botulinum toxin A continue to be effective in controlling patient's epiphora up to 5 years [12].

Patients with epiphora can be efficiently treated with BoNT/A. They are very satisfied with fewer side effects (transient ptosis). Injection of BoNT/ A in the palpebral lobe of principal lacrimal gland is safe and effective for epiphora even in lacrimal ducts obstruction. This outdoor-treatment is reliable, reproducible, constant and painless. More studies are needed to specify the therapeutic protocol. 


\section{REFERENCES :}

1-Riemann R, Pfennigsdorf S, Riemann E et al. Successful treatment of crocodile's tears (gustatory epiphora) by injection of botulinum toxin into the lacrimal gland:a case report. Ophthalmology 1999; 106:2322-4

2-Hofmann RJ. Treatment of Frey's syndrome (gustatory sweating) and crocodile's tears (gustatory epiphora) with purified botulinum toxin. Ophthal Plast Reconstr Surg 2000;16:289-91

3-Montoya FJ, Riddell CE, Hague S. Treatment of gustatory hyperlacrimation (crocodile tears) with injection of botulinum toxin into the lacrimal gland. Eye 2002;16:705-9.

4-Keegan DJ, Geerling G, Lee JP, Blake G, Collin JR, Plant GT. Botulinum toxin treatment for hyperlacrimation secondary to aberrant regenerated seventh nerve palsy or salivary gland transplantation. Br J Ophthalmol 2002;86:43-6.

5-Naumann M. Evidence-based Medicine: botulinum toxin in focal hyperhidrosis. J Neurol 2001;248:31-3.

6-Naumann M, Lowe NJ. Botulinum toxin type $A$ in treatment of bilateral primary axillary hyperhidrosis: randomised, parallel group, double blind, placebo controlled trial. BMJ 2001;15;323(7313):596-9.

7-Naumann M, Jost W. Botulinum toxin of secretory disorders. Mov Disord. 2004;19S8:137-41.

8-Wabbels B, Förl M. Botulinum toxin treatment for crocodile tears, spastic entropion and for dysthyroid upper lid retraction. Ophthalmologe 2007;104:771-6.

9-Nava-Castaneda A, Tovilla-Canales JL, Boullosa V, Tovilla-y-Pomar JL, Monroy-Serrano MH, TapiaGuerra V., Duration of botulinum toxin effect in the treatment of crocodile tears. Ophthal Plast Reconstr Surg 2006;22:453-6.

10- Boroojerdi B, Ferbert A, Schwarz M, Herath H, Noth J. Botulinum toxin treatment of synkinesia and hyperlacrimation after facial palsy. J Neurol Neurosurg Psychiatry 1998;65:111-14.

11-Keegan DJ, Geerling G, Lee JP, Blake G, Collin JR, Plant GT. Botulinum toxin treatment for hyperlacrimation secondary to aberrant regenerated seventh nerve palsy or salivary gland transplantation. Br J Ophthalmol 2002;86:43-6.

12-Barañano DE, Miller NR. Long term efficacy and safety of botulinum toxin A injection for crocodile tears syndrome. Br J Ophthalmol 2004;88:588-9.

13-Wojno TH. Results of lacrimal gland botulinum toxin injection for epiphora in lacrimal obstruction and gustatory tearing. Ophthal Plast Reconstr Surg 2011; 27:119-121.

14-Ziahosseini K, Al-Abbadi Z, Malhotra R. Botulinum toxin injection for the treatment of epiphora in lacrimal outflow obstruction. Eye 2015;29:656-661.

15-Whittaker KW, Matthews BN, Fitt AW, Sandramouli S. The use of botulinum toxin A in the treatment of functional epiphora. Orbit. 2003 Sep;22(3):193-8.

16- Girard B, Piaton J-M, Keller P, Levy P, Laroche L : Neurotoxin Botulinum A in the treatment of epiphora. Toxin's 2012 . 
TABLE 1: Munk score

\begin{tabular}{|c|l|}
\hline grade & \\
\hline 0 & No Epiphora. \\
\hline 1 & Occasional epiphora requiring drying or dabbing less than twice a day. \\
\hline 2 & Epiphora requiring dabbing two to four times per day. \\
\hline 3 & Epiphora requiring dabbing five to ten times per day. \\
\hline 4 & Epiphora requiring dabbing more than ten times daily or constant tearing. \\
\hline
\end{tabular}


TABLE 2 : tearing improving after BoNT/A injection ; pre-injection and post-injection scores

\begin{tabular}{|l|c|c|c|}
\hline & mean & SD & median \\
\hline Munk score pre & 3.88 & 0.3 & 4 \\
\hline Munk score post & 0.5 & 0.8 & 40 \\
\hline Schirmer test pre & 35 & 18 & 12 \\
\hline Schirmer test post & 13 & 2.5 & \\
\hline
\end{tabular}


Table 3 : complications

\begin{tabular}{|l|c|c|c|c|}
\hline Lacrimal gland & ptosis & $\%$ & diplopia or esotropia & $\%$ \\
\hline 27 & 4 & 14 & 2 & 0.7 \\
\hline 14 & 4 & 28 & 0 & 0 \\
\hline 7 & 0 & 0 & 1 & 1.4 \\
\hline 2 & 0 & 0 & & 0 \\
\hline 1 & 0 & 0 & 0 & 0 \\
\hline
\end{tabular}


Table 4 : Results in litterature

\begin{tabular}{|c|c|c|c|c|}
\hline & BG et al & $\begin{array}{c}\text { Wojno } \\
{[13]}\end{array}$ & $\begin{array}{l}\text { Whittaker } \\
{[15]}\end{array}$ & $\begin{array}{l}\text { Ziahosseini } \\
{[14]}\end{array}$ \\
\hline $\begin{array}{l}\text { Mean } \\
\text { units/gland }\end{array}$ & $2-10 \mathrm{U}$ & $2.5 \mathrm{U}$ & $2.5-5 \mathrm{U}$ & $2.5-7,5 \mathrm{U}$ \\
\hline $\begin{array}{l}\text { N. Lacrimal } \\
\text { glands }\end{array}$ & 27 & 27 & 11 & 22 \\
\hline EFFICACY & 93 & 74 & 75 & 70 \\
\hline ptosis & 14 & 11 & 18 & 0 \\
\hline Diplopia & 7 & 0 & 18 & 12 \\
\hline dryness & 0 & 0 & 0 & 0 \\
\hline hematoma & 0 & 0 & 0 & 7 \\
\hline
\end{tabular}


NEUROTOXIN BOTULINUM A IN THE TREATMENT OF EPIPHORA IN

LACRIMAL DUCTS OBSTRUCTION

TABLE 1: Munk score

\begin{tabular}{|c|l|}
\hline grade & \\
\hline 0 & No Epiphora. \\
\hline 1 & Occasional epiphora requiring drying or dabbing less than twice a day. \\
\hline 2 & Epiphora requiring dabbing two to four times per day. \\
\hline 3 & Epiphora requiring dabbing five to ten times per day. \\
\hline 4 & Epiphora requiring dabbing more than ten times daily or constant tearing. \\
\hline
\end{tabular}


TABLE 2 : tearing improving after BoNT/A injection ; pre-injection and post-injection scores

\begin{tabular}{|l|c|c|c|}
\hline & mean & SD & median \\
\hline Munk score pre & 3.88 & 0.3 & 4 \\
\hline Munk score post & 0.5 & 0.8 & 0 \\
\hline Schirmer test pre & 35 & 18 & 40 \\
\hline Schirmer test post & 13 & 2.5 & 12 \\
\hline
\end{tabular}


Table 3 : complications

\begin{tabular}{|l|c|c|c|c|}
\hline Lacrimal gland & ptosis & $\%$ & diplopia or esotropia & $\%$ \\
\hline 27 & 4 & 14 & 2 & 0.7 \\
\hline 14 & 4 & 28 & 0 & 0 \\
\hline 7 & 0 & 0 & 1 & 1.4 \\
\hline 2 & 0 & 0 & & 0 \\
\hline 1 & 0 & 0 & & 0 \\
\hline
\end{tabular}


Table 4

\begin{tabular}{|l|l|l|l|l|}
\hline & BG et al & Wojno & Whittaker & Ziahosseini \\
& & {$[13]$} & {$[15]$} & {$[14]$} \\
\hline $\begin{array}{l}\text { Mean } \\
\text { units/gland }\end{array}$ & $2-10 \mathrm{U}$ & $2.5 \mathrm{U}$ & $2.5-5 \mathrm{U}$ & $2.5-7,5 \mathrm{U}$ \\
\hline N. Lacrimal & 27 & 27 & 11 & 22 \\
\hline glands & & & & \\
\hline EFFICACY & 93 & 74 & 75 & 70 \\
\hline ptosis & 14 & 11 & 18 & 0 \\
\hline Diplopia & 7 & 0 & 18 & 12 \\
\hline hryness & 0 & 0 & 0 & 0 \\
\hline
\end{tabular}

